\title{
Study of the magnetization loss of CORC cables using 3D T-A formulation
}

\author{
Yawei Wang ${ }^{1}$, Min Zhang ${ }^{1 *}$, Francesco Grilli², Zixuan Zhu ${ }^{1,3}$, Weijia Yuan ${ }^{*}$ \\ ${ }^{1}$ Department of Electronic and Electrical Engineering, University of Strathclyde, G1 1XQ, Glasgow, UK. \\ ${ }^{2}$ Institute for Technical Physics, Karlsruhe Institute of Technology (KIT), 76131, Karlsruhe, Germany. \\ ${ }^{3}$ Department of Electronic and Electrical Engineering, University of Bath, BA27AY, Bath, UK.
}

E-mail: min.zhang@strath.ac.uk; weijia.yuan@strath.ac.uk

\begin{abstract}
Conductor on round core (CORC) cable wound with high temperature superconductors (HTS) is an important cable concept for high current density applications. The design of CORC cable makes the understanding of its electromagnetic performance - for example its AC losses - challenging. This paper presents a thorough study for CORC cables by combining experimental and numerical methods. In particular, the paper focuses on understanding how the cable structure influences the magnetization losses and on how these can be reduced. A novelty of this paper lies in the use of a new T-A formulation, which, for the first time, is employed for 3D modelling of CORC cable with real geometry. The use of the new T-A formulation in finite element software enables the study of how the winding direction and multiple-layer structure affect the magnetization losses of CORC cables. Moreover, influence of striation in CORC cable is studied as an effective way to reduce its losses. The CORC cable with striated tapes shows a significant magnetization loss reduction at high magnetic fields, in comparison to its un-striated counterpart. At low magnetic fields, tape striation leads to a loss rise when the number of filaments is low, then the loss drops with the further increase of filaments, but this loss reduction is much weaker than that at high fields. The paper provides an efficient tool for investigating the electromagnetic behaviour of CORC cables, which can provide valuable guidance in designing CORC cables with minimized losses for high energy physics and energy conversion applications.
\end{abstract}

Keywords: CORC cable, Magnetization loss, 3D modelling, T-A formulation. 


\section{Introduction}

The second generation (2G) high temperature superconductor (HTS), ( $R E) \mathrm{Ba}_{2} \mathrm{Cu}_{3} \mathrm{O}_{x}$ (REBCO) coated conductor has a definite advantage of high current density, high critical current and cost reduction potential, compared with first generation HTS, BiSCCO[1, 2]. These features make it a promising candidate for many industry applications with large current, e.g. power transmission, low-inductance magnets and high field magnets [3-15]. To circumvent the current limitation of a single REBCO conductor, three main cabling concepts have been developed: Roebel cables[16-20], twisted stack cable[21, 22], and conductor on round core (CORC) cable[23-26].

The CORC cable is based on winding REBCO tapes helically on a round core, and it has a great advantage of flexibility, mechanical strength and easy manufacturing, compared with other cabling approaches $[23,25]$. With a transposition on all the tapes in each layer, the CORC cable approach is effective in reducing the coupling currents in REBCO tapes, as well as magnetization loss. This has been validated experimentally in previous studies [26-29]. To further reduce the magnetization AC loss, researchers proposed to divide single tapes into multi-filaments[30-36]. Measurements proved that CORC cable wound from striated tapes shows a reduction of magnetization loss at high magnetic field $[37,38]$. Two-dimensional (2D) modelling analyses have been conducted on CORC cables [39-44]. These calculations of magnetization loss show considerable error for cables with short pitch, without the consideration of winding pitches and winding directions. An improved 2D model has been developed by considering the spiral structure of CORC cable to calculate its self-field hysteresis loss [45]. A 3D model based on $\mathrm{H}$-formulation was built with simplified structure, optimized assumptions and settings[40]. However, the 3D H-formulation model always suffers the problem of meshing and convergence due to the high aspect ratio, which limits its application to complicated geometry. Amemiya's group has developed a three-dimensional (3D) model for CORC cables by coupling differential equation (Faraday's law) and integration equation (Biot-Savart law)[46, 47].

This paper presents, for the first time, a new 3D model for CORC cables using T-A formulation and commercial finite element software $[48,49]$. The 3D model is used to study the magnetization losses of CORC cables, supported by calibration-free magnetization loss measurement for CORC cables published earlier. A detailed study of the magnetization loss of CORC cable is performed, and the distribution of local current induced by transverse fields is analyzed. Single tape and several different CORC cable models are compared in the view of magnetization loss. The influence of winding direction and air gap position on the magnetization loss is analyzed based on a double-layer CORC cable model. The 
distribution of magnetization loss among layers in a multiple-layer CORC cable is also studied based on cable models with three and four layers. Finally, the loss reduction generated by striation technique is analyzed using the proposed model, and the influence of filament number on magnetization loss is discussed at low applied fields and high applied fields.

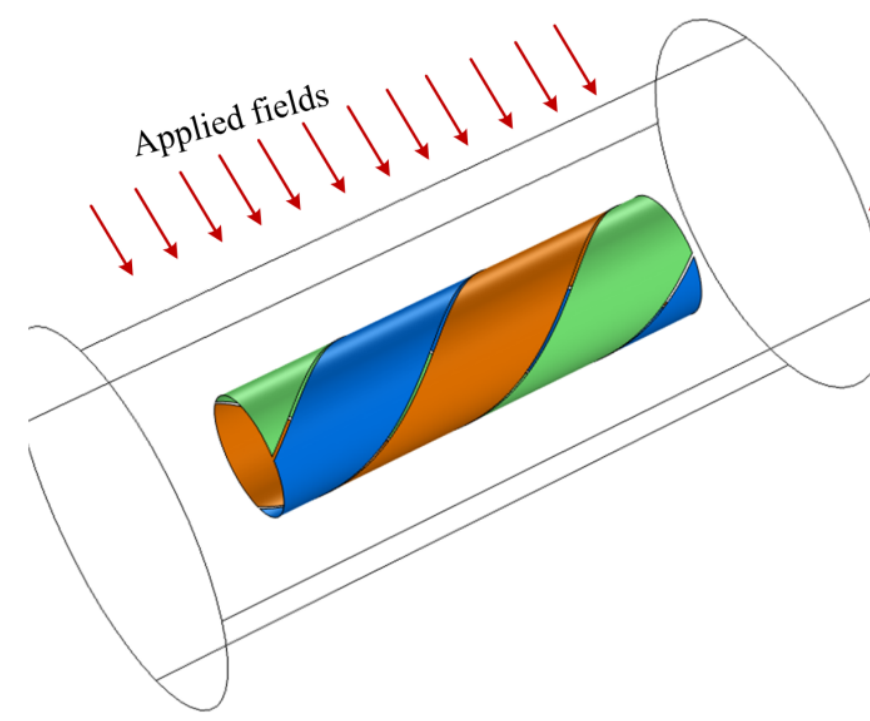

(a)
Boundary of A-formulation model

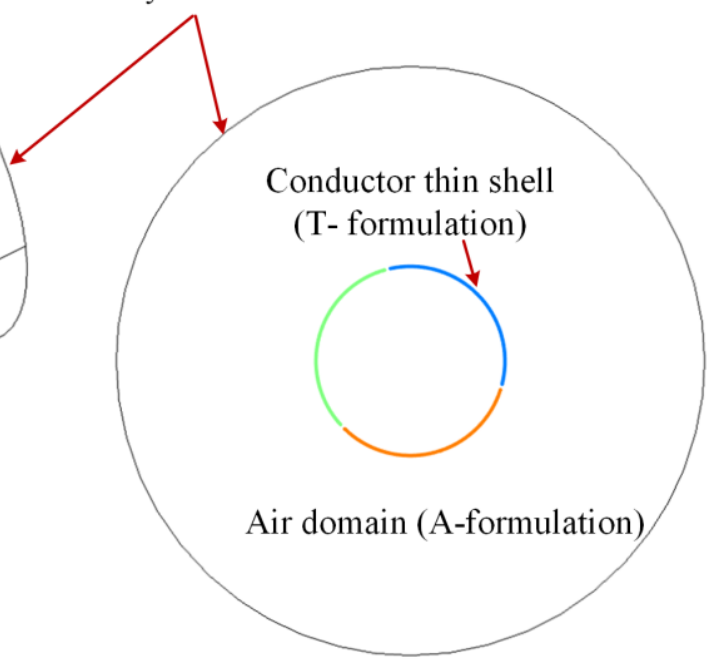

(b)

Figure 1. Schematic illustration of the CORC cable model, (a) 3D model, (b) Cross section of the 3D model.

\section{3D model for CORC cable}

A 3D numerical model for the CORC cable is developed based on our new T-A formulation and finite element method (FEM). The advantage of the T-A formulation is that it treats the REBCO layer as an infinitely thin shell, therefore reducing the calculation difficulty associated with the high aspect ratio of REBCO $[46,47]$. By effectively coupling the $T$ and A potentials, the T-A formulation enables an easy calculation of both current and magnetic fields. Based on this simplification, a 3D numerical model is built for the CORC cable using T-A formulation and finite element method. The governing equation based on T-formulation is derived from Faraday's law, which is applied on the conductor shell only to calculate the current distribution; the governing equation based on A-formulation is derived from Ampere's law, which is applied on all the domains to calculate the magnetic field distribution, as shown in Figure 1(b) $[48,49]$. Both models are built and solved in COMSOL Multiphysics: This T- formulation model is solved 
in the PDE module and the A-formulation model is solved in a magnetic field module, making the 3D modeling of CORC cable practical, easy and extendable.

\subsection{T-formulation}

A current vector potential $\mathbf{T}$ is defined by the current density J:

$$
\mathbf{J}=\nabla \times \mathbf{T}
$$

On the conductor shell, the current only has a component tangential to the tape surface, the current vector potential $\mathbf{T}$ is always perpendicular to the tape surface. Therefore, on the conductor shell domain, the above equation can be rewritten as [47-50]:

$$
\mathbf{J}=\nabla \times(T \mathbf{n})
$$

where the scalar $T$ is the normal component of $\mathbf{T}, \mathbf{n}$ is the unit normal vector of the tape surface.

The governing equation on the conductor shell is derived from Faraday's law:

$$
\nabla \times \mathbf{E}(\nabla \times(T \mathbf{n}))=-\frac{\partial \mathbf{B}}{\partial t}
$$

where the electric field $\mathbf{E}$ is a function of current density $\mathbf{J}$. The magnetic field $\mathbf{B}$ here is not solved and calculated in the iteration of Eq. (3). It will be obtained directly from the A-formulation model in the following section. The E-J relationship of REBCO conductor is expressed as:

$$
\mathbf{E}(\mathbf{J})=E_{0}\left(\frac{|\mathbf{J}|}{J_{c}(\mathbf{B})}\right)^{n} \frac{\mathbf{J}}{J_{c}(\mathbf{B})}
$$

where $E_{0}=1 \times 10^{-4} \mathrm{~V} / \mathrm{m}$ and $n=31$ for the tape used in this study. $J_{c}$ is the critical current density and its field dependence is expressed as follows [51]:

$$
J_{c}(\mathbf{B})=J_{c}\left(B_{p a r}, B_{p e r}\right)=\frac{J_{c 0}}{\left[1+\sqrt{\left(k B_{p a r}\right)^{2}+B_{p e r}^{2}} / B_{c}\right]^{b}}
$$

where $B_{p a r}$ and $B_{p e r}$ represent the magnetic field component parallel and perpendicular to the tape surface respectively. $J_{c o}$ is the critical current density in the absence of any fields. $k, b, B_{c}$ are shape parameters representing the field anisotropic characteristics of REBCO conductors, and in this study, $k=$ $0.0605, b=0.7580$, and $B_{c}=103 \mathrm{mT}$.

The magnetization loss energy induced in superconducting layers is calculated by [52-56]:

$$
Q=2 \int_{T / 2}^{T} \mathrm{dt} \int_{\Omega} \mathbf{E} \cdot \mathbf{J d} \Omega
$$

where $Q$ has a unit of Joule per cycle; $T=1 / f, f$ is the frequency. Merging the Eq. 2, 4, 5 into Eq. 3, the state variable of the governing equation is transferred to scalar variable $T$. A vector problem with three 
variables in 3D space is reduced to a problem of the scalar variable $T$ in a $2 \mathrm{D}$ thin shell, which significantly reduces the computation cost.

\subsection{A-formulation}

The $\mathbf{A}$-formulation model is applied on the 3D domain to calculate the magnetic field, as shown in the Figure 1. The governing equation is derived from Ampere's law:

$$
\left\{\begin{array}{l}
\nabla \times \nabla \times \mathbf{A}=0 \\
\mathbf{B}=\nabla \times \mathbf{A}
\end{array}\right.
$$

where $A$ is the magnetic potential. A surface current $J_{s}$ occurs on the conductor shell only. It is obtained from the above T-formulation model and is calculated from Eq. (2). Therefore, a boundary condition is imposed on the conductor shell, as follows:

$$
\mathbf{n} \times\left(\mathbf{H}_{2}-\mathbf{H}_{1}\right)=\mathbf{J}_{s}
$$

where $\mathbf{H}_{1}$ and $\mathbf{H}_{2}$ are the magnetic field on the two sides of the conductor shell.

To simulate the external magnetic field applied, a Dirichlet Neumann boundary condition is imposed on the outer boundary of the 3D domain.

$$
\mathbf{B}=\left(\begin{array}{lll}
B_{0} \sin (2 \pi f t) & 0 & 0
\end{array}\right)
$$

where $B_{0}$ and $f$ are the magnitude and frequency of the magnetic field respectively. The calculated magnetic field B is fed back to Eq. (3) and Eq. (5) in the $T$-formulation model.

\section{Model validation}

In order to validate the model, AC losses were calculated and compared to those published in [38]. The geometrical and physical properties were chosen in accordance with [38], as shown in Table 1. Two CORC cable samples are wound from REBCO tapes, which are named as Cable B and Cable C. Cable B has two layers and each layer is wound with 3 tapes. The inner layer has an anticlockwise winding direction and the outer layer has a clockwise direction, which is called opposite winding direction structure in this study. Cable $\mathrm{C}$ has three layers, and each layer is also wound with 3 tapes. The adjacent two layers have an opposite winding direction. More details about them are shown in Table 1. The REBCO tape has a width of $4 \mathrm{~mm}$ and a thickness of $0.1 \mathrm{~mm}$. The thickness of superconducting layer is assumed to be 1 $\mu \mathrm{m}$. The substrate is Hastelloy, and a copper stabilizer is present on both sides of the tape. The critical current of the tape is $100 \mathrm{~A}$ in self-field at $77 \mathrm{~K}$. No terminations is applied on the ends of the cable, therefore no coupling current is induced between individual tapes $[26,37]$. In the cables discussed in 
[38], both edges of the tape were cut to prevent coupling current through copper on the edge. In the simulation, only the superconducting layers are simulated and they are separated by air (no electrical coupling between them). Figure 2 compares the magnetization loss from measurement and simulation. The magnetization loss is the total losses of two layers with a unit of Joule per cycle per meter (along the axial direction). The results from the above model show a good agreement with data from measurements.
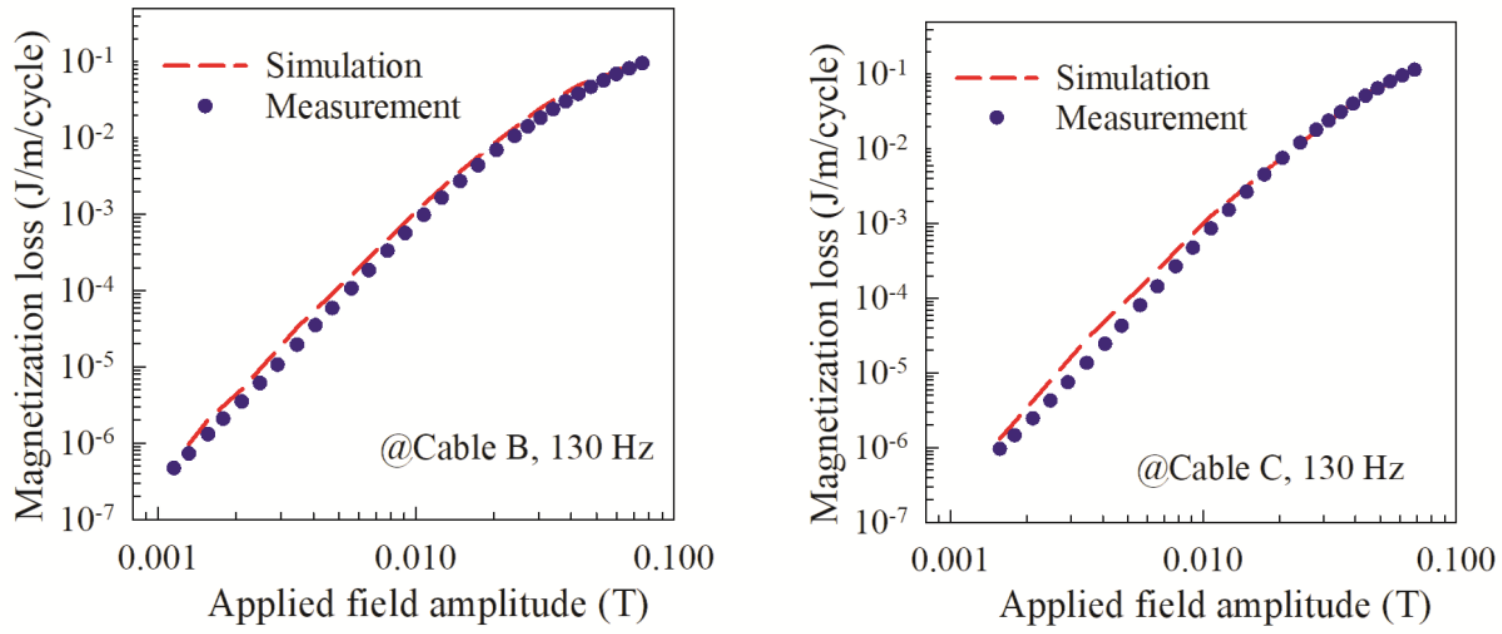

Figure 2. Magnetization loss, in Joule per cycle per meter of cable length, of two cable samples of measurements from [27] and simulation.

Table 1. Specification of the CORC cable sample studied[38]

\begin{tabular}{llll}
\hline Parameters & Cable A & Cable B & Cable C \\
\hline Number of layers & 1 & 2 & 3 \\
Tapes per layer & 3 & 3 & 3 \\
Diameter of layers & $5.14 \mathrm{~mm}$ & $5.14 / 5.24 \mathrm{~mm}$ & $5.14 / 5.24 / 5.42 \mathrm{~mm}$ \\
Winding direction & $/$ & Opposite & Opposite \\
Angle & $40^{\circ}$ & $40^{\circ}$ & $40^{\circ}$ \\
Pitch & $19 \mathrm{~mm}$ & $19 \mathrm{~mm}$ & $19 \mathrm{~mm}$ \\
$I_{c}$ @77 K & $300 \mathrm{~A}$ & $607 \mathrm{~A}$ & $904 \mathrm{~A}$ \\
\hline
\end{tabular}

\section{Results and discussion}




\subsection{Distribution of induced current and magnetization loss}

We compare the calculated magnetization AC loss of four samples: single REBCO tape, CORC cable with single layer (Cable A), CORC cable with two layers (Cable B), CORC cable with three layers (Cable C). The single REBCO tape is the same one that used in the three cable samples, and the applied field is perpendicular to the tape surface in the simulation. Cable B and Cable $C$ are the cable model tested in Section 3. Cable $A$ is the single layer counterpart of Cable B and Cable $C$, and its specification is shown in Table 1. The magnetization loss of the four samples is shown in Figure 3. Notice that, for a better comparison, the magnetization loss here has a unit of Joule per cycle per meter of REBCO tapes $Q_{\text {tape, }}$ while that in Figure 2 is the total magnetization loss of all the tapes on the cable $Q_{\text {cable. }}$ Their relationship can be expressed as follows:

$$
Q_{\text {tape }}=\frac{Q_{\text {cable }}}{N_{\text {tape }}} \cos \alpha
$$

Here the $N_{\text {tape }}$ is number of tapes used in the cable, and $\alpha$ is the winding angle. The results show that the magnetization loss in the tape of CORC cable is much lower than that in the single tape. Figure 4 shows the distribution of induced magnetization current on one of REBCO tapes in Cable A during a period of the applied field, the other two tapes have a same current distribution due to the symmetric geometry structure. Figure 4(c) and Figure 4(d) are from the view parallel and perpendicular to the applied field respectively. The results show two magnetization current loops are induced within a pitch on the tape zones perpendicular to the applied transverse field, in which magnetization loss is generated. The adjacent current loops have opposite current flowing direction, and they meet at the tape zones parallel to the applied transverse field, and therefore the current, along with the magnetization loss, of these zones are much lower than other zones. For the single tape exposed in applied fields, only one large magnetization current loop is induced on the tape. In CORC cables, the induced magnetization current is divided into small local current loops by the helical winding structure. Therefore, the magnetization loss in CORC cable is much lower than that in single tape, which agrees well with previous measurements[26].

The results in Figure 3 also show that the magnetization loss per unit tape length reduces with the increase of cable layers. With the same applied field, overlapped REBCO tapes have field-shielding effects on each other, and therefore the CORC cable with more layers means less induced current on each tape. This field shielding is more significant at low applied fields, and thus leads to a more significant magnetization loss reduction in low magnetic fields. With the increase of applied fields, the 
penetration increases rapidly, and the field shielding effects decreases continuously, thus the loss reduction generated by multiple layers is less obvious for high magnetic fields.

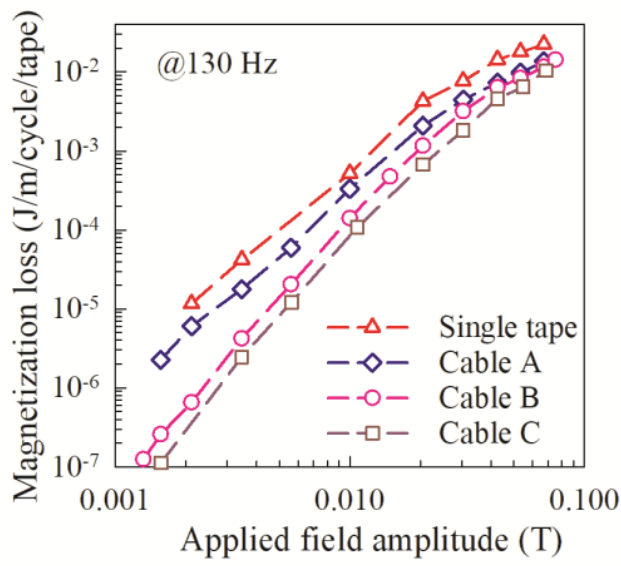

Figure 3. Magnetization loss calculated, in Joule per cycle per meter of REBCO tape length, $Q_{\text {tape }}$ of the single REBCO tape, Cable A with one layer, cable B with two layers, cable C with three layers.

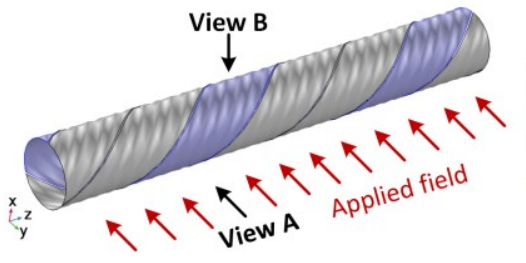

(a) Schematic illustration of view A and B

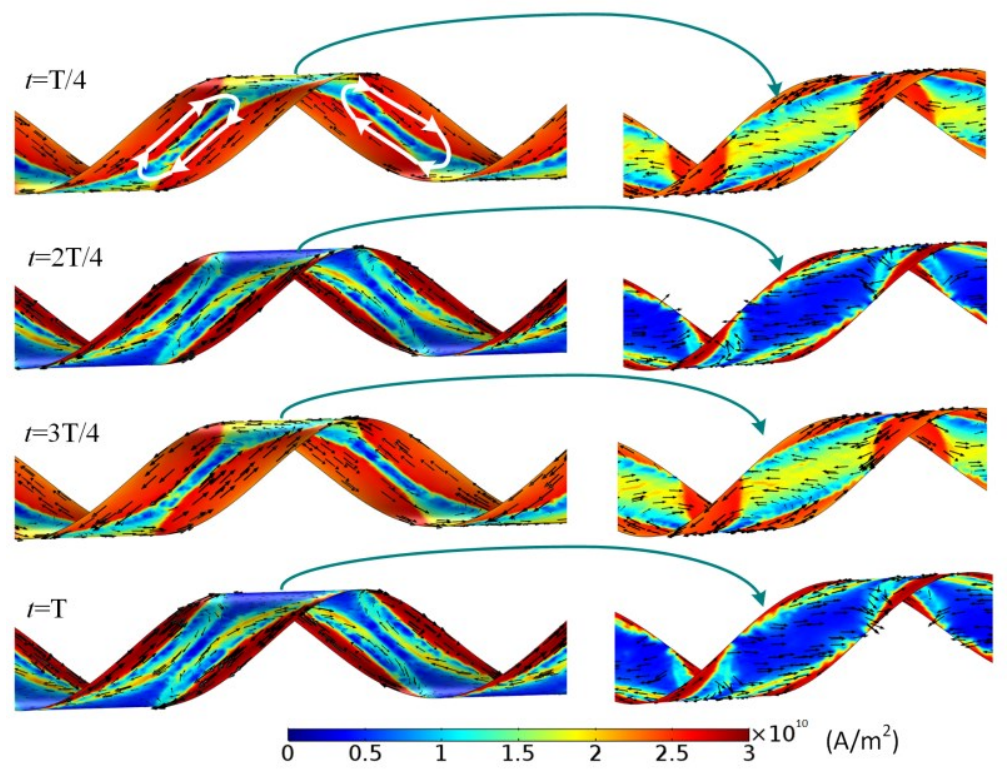

(c) current density (View A)

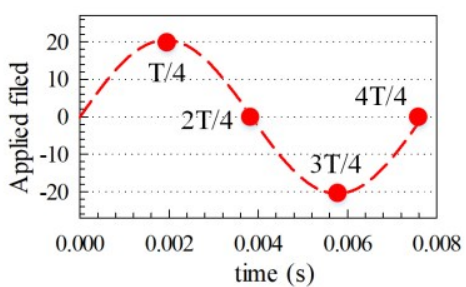

(b) applied field (d) current density (View B) 
Figure 4. Distribution of the induced current density on the REBCO tape of single layer CORC cable (Cable A), exposed in an AC transverse applied field, $20.5 \mathrm{mT} / 130 \mathrm{~Hz}$.

\subsection{Influence of winding direction}

In this section, we study how the winding direction of CORC cables affects the magnetization loss of CORC cables with multiple layers. In our previous discussions, Cable B has 2-layer tapes in opposite winding directions. For comparison, we simulated the magnetization loss of two counterparts of Cable B, Cable B2 and Cable B3, in which the two layers have the same winding direction. In Cable B2, the two layers are perfectly aligned, so that the air gap in the inner layer matches perfectly to that in the outer layer. In the Cable B3, the air gap in inner layer is aligned with middle of the outer layer. The magnetization losses of the three cables are plotted in Fig. 5. The results show that Cable B2 with perfectly aligned air gap generates lowest magnetization loss, and Cable B3 with middle aligned gap generates highest magnetization loss. To understand this, we plot in Fig. 6 the current distribution of the three cable models. In Cable B2, the two overlapping tapes have almost same induced current distribution and same flowing direction of current loops. This enables the two induced current loops to have a better field shielding effect on each other in comparison to the other cables, which is an important factor leading to the lowest magnetization loss. In Cable B and Cable B3, the overlap areas of current loops induced on the same position of two layers are smaller than that of Cable B2, and the induced current patterns on different layers are different. This leads to a relatively weaker field-shielding effect, thus increasing the magnetization loss.

We also chose three cross-sections on the three cable models, as shown in Figure 6. The distribution of normalized current density $\left(\mathrm{J} / \mathrm{J}_{\text {norm }}\right)$ and magnetic field lines on the three cross-sections is plotted in Figure 7. In Cable B2, the air gap in the inner layer always matches perfectly with that in the outer layer in different cross-sections, and the position of the induced current in two layers is always corresponding to the position of the air gap. The transverse field always penetrates the CORC cables through air gaps. In Cable B3, the magnetic fields penetrating through the air gap of the outer layer have to penetrate the inner layer directly through the HTS tapes, thus generates more induced current and magnetization loss. Besides the influence of air gaps, the position of the induced current in Cable B3 mainly depends on the direction of transverse fields, and most of the induced current occurs on the tape zones perpendicular to the transverse field. In Cable B with opposite winding direction, the relative position of air gaps in two layers is very different on different cross-sections. Cross-section 1 is the cross point of the air gaps in two layers. The distribution of induced current and magnetic field lines shows a similar trend to that 
on Cable B2. On cross-section 2, the air gap of the inner layer is aligned with middle of the outer layer, thus the distribution of magnetic field lines shows a similar trend to that on Cable B. The distributions of magnetic field lines and induced current on cross-section 3 show an intermediate situation between those of the above two cross-sections. Therefore, total magnetization loss in Cable B is between that of Cable B2 and Cable B3.

CORC cables are often wound with an opposite winding direction on adjacent layers due to the enhanced mechanical performance and low inductance. The above analysis shows that cable model B2 with same winding direction has a lower magnetization loss than the cable model B with opposite winding direction. However, it is not easy and practical to align perfectly the air gaps of two adjacent layers in the fabrication of CORC cables. For cables with same winding direction, if the air gaps in different layers are not aligned well enough, the cable may generate more magnetization loss than the Cable B. Therefore, the cable model B with opposite winding direction is a more reasonable design in view of practicability and magnetization loss reduction.

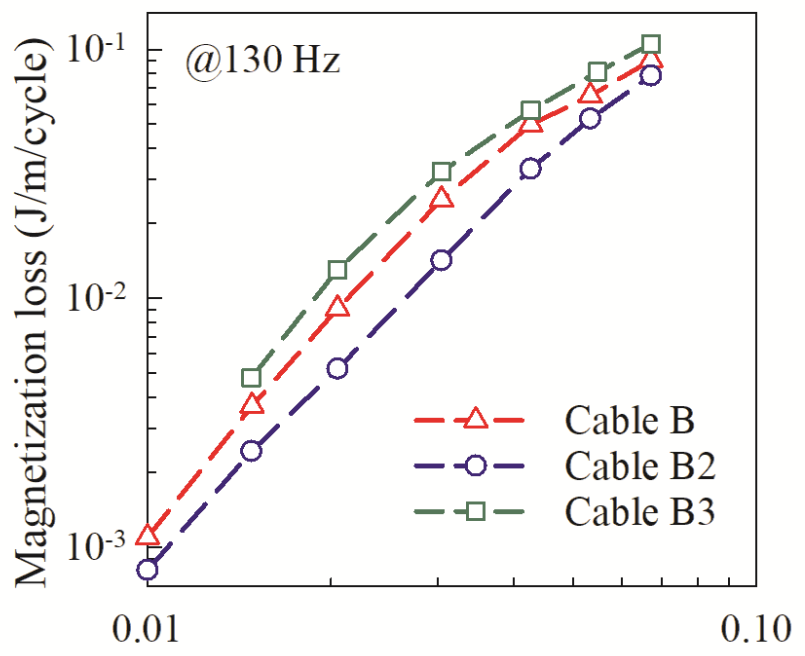

Applied field amplitude (T)

Figure 5. Magnetization loss calculated, in Joule per cycle per meter of cable length, $Q_{\text {cable }}$ of Cable B having two layers in opposite winding direction and its two counterparts with same winding direction, Cable B2 and Cable B3. In Cable B2, the gaps of two layers are perfectly aligned at same position; in Cable B3, the gap in inner layer is aligned with middle of the outer layer. 


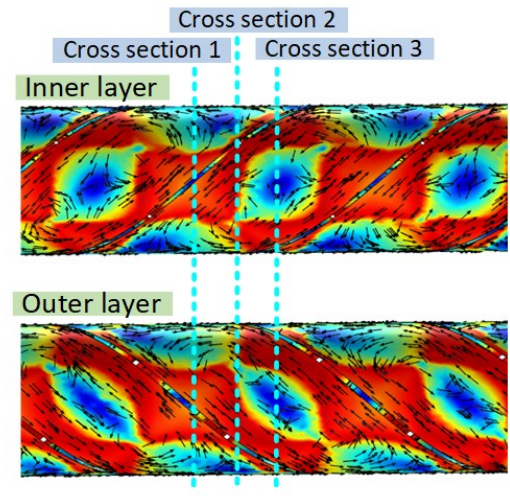

(a) Cable B, opposite winding direction.

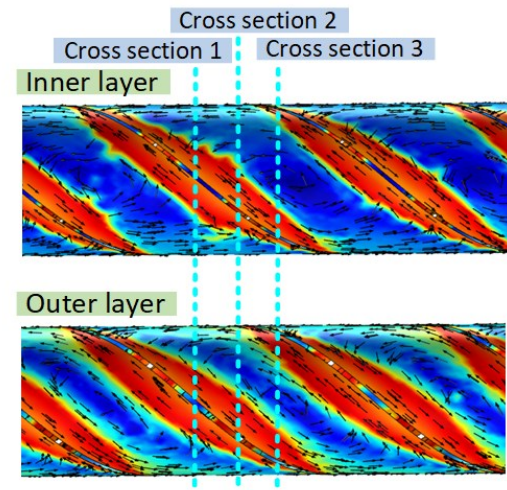

(b) Cable B2, same winding direction, gap perfectly aligned.

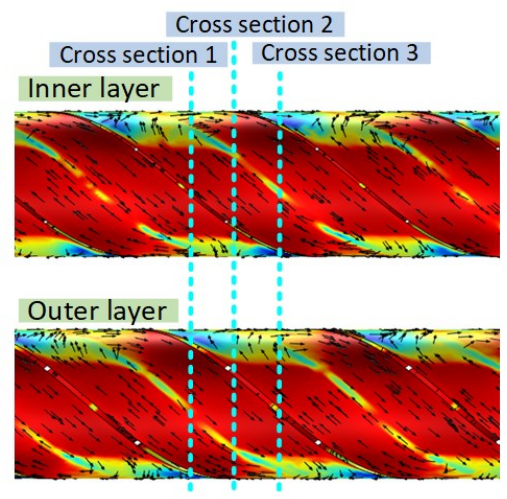

(c) Cable B3, same winding direction, gap middle aligned.

(View A) $\begin{array}{llllll}0 & 0.5 & 1 & 1.5 & 2 & 2.5\end{array} \times 10^{4}(\mathrm{~A} / \mathrm{m})$

Figure 6. Distribution of the induced current density on the two layers of Cable B (opposite winding direction) and its counterparts with same winding direction, Cable B2 and Cable B3, $t=3 T / 4$, the applied field, $20.5 \mathrm{mT} / 130 \mathrm{~Hz}$.

Cross-section 1
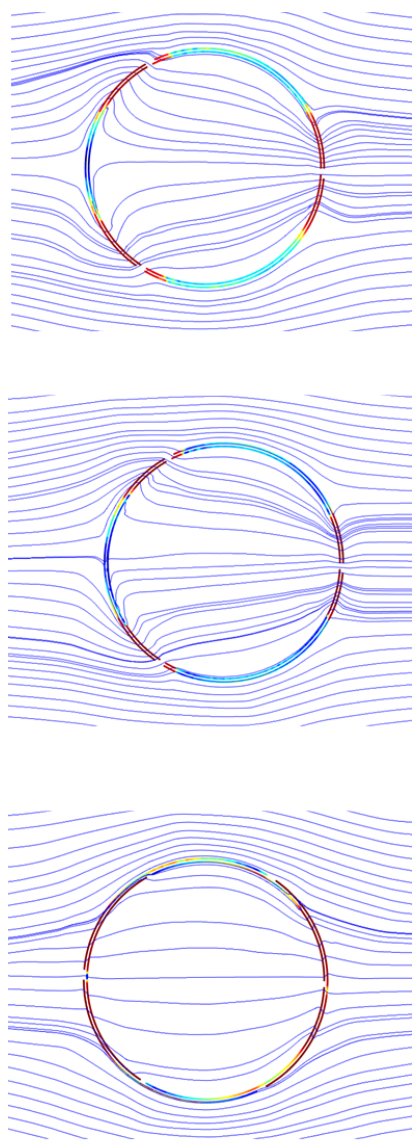

Cross-section 2

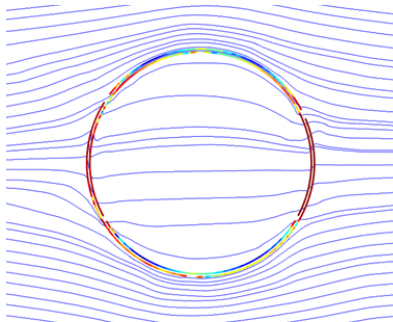

(a) Cable B

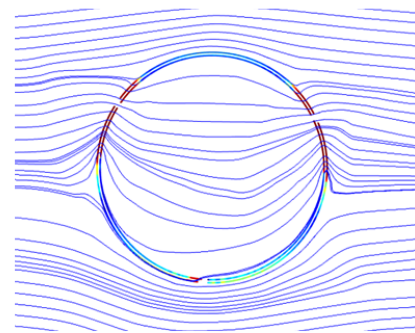

(b) Cable B2

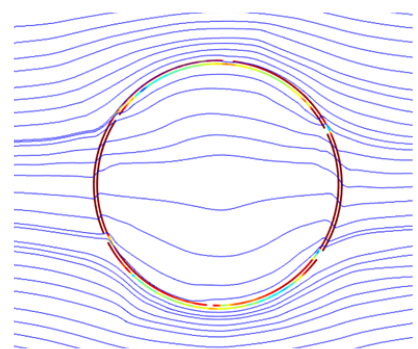

(c) Cable B3
Cross-section 3

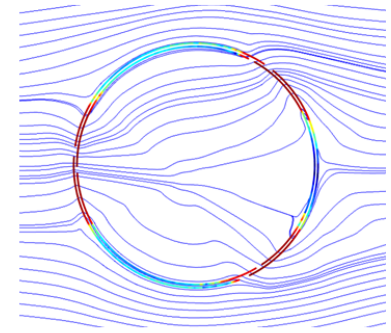

1

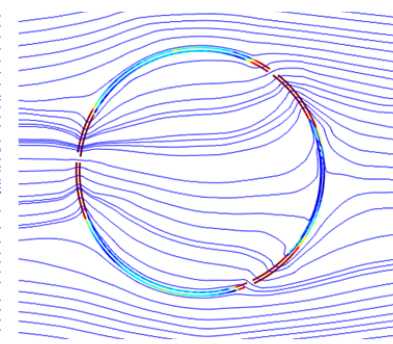

0.8

0.6

0.4

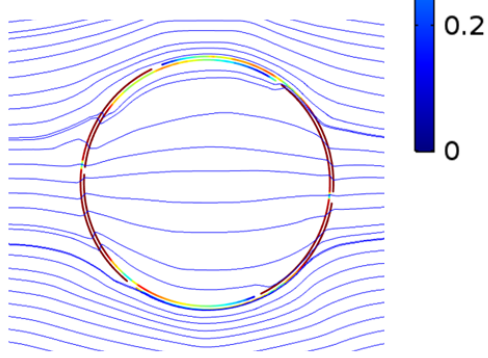

0.2 
Figure 7. Normalized current density $\left(J / J_{\text {norm }}\right)$ and magnetic field penetration on the three cross sections of Cable B, Cable B2 and Cable B3, $t=3 \mathrm{~T} / 4$, the applied field, $20.5 \mathrm{mT} / 130 \mathrm{~Hz}$. The colour bar is for the Normalized current density $\left(J / J_{\text {norm }}\right)$.

\subsection{Distribution of magnetization loss among layers}

In this section, we study the distribution of the magnetization loss among layers in CORC cable with multiple-layers. Figure 8 shows the magnetization loss of three layers in Cable $\mathrm{C}$. The middle layer, which has an opposite winding direction with respect to the outer and inner layers, generates higher magnetization loss than the other two layers; while the magnetization loss on the inner and outer layers are similar. By changing the winding direction of separate layers, we conceptually designed cable C2, C3 and $\mathrm{C} 4$ as reference models and simulated their magnetization loss. In Cable $\mathrm{C} 2$, the inner layer has an opposite winding direction with respect to the outer and middle layers; In Cable C3, the outer layer has an opposite winding direction in respect to the middle and inner two layers; In cable $\mathrm{C} 4$, the three layers have the same winding direction and the air gaps of three layers are perfectly aligned. Notice that in Cable C, C2 and C3, the air gaps in the two layers with same winding direction are also perfectly aligned. The distribution of magnetization loss among layers for Cable $C, C 2, C 3$ and $C 4$ is shown in Figure 9. The results show that the magnetization loss in Cable $\mathrm{C} 4$ has an approximately uniform distribution among layers. In the other three cable models, the two layers with perfectly aligned air gap have an almost same magnetization loss to that in Cable C4, while the layer with an opposite winding direction with respect to the other layers always has a much higher magnetization loss than the other two layers. Figure 10 shows the current distribution of three layers of Cable C, C2 and C3. The perfectly-aligned two layers with the same winding direction have stronger field shielding effects on each other, while the layer with the opposite winding direction sees more penetration of magnetic field through the air gap of other layers, and thus generating higher magnetization loss [57, 58].

Figure 11 shows the distribution of magnetization loss among layers of two CORC cable models with four layers, Cable D and Cable D2. Cable D is a four-layer counterpart part of Cable C, and the air gaps of the four layers are perfectly aligned at the same position. Here the four layers are numbered 1 4 from the inner layer to the outer layer. Cable D2 is obtained by changing the winding direction of layer 2 and layer 4 of Cable D. Magnetization loss shows an approximately uniform distribution among the four layers of Cable D and Cable D2. The above analysis show that the distribution of magnetization loss among layers significantly depends on the relative position of air gaps in each layers. For CORC cable with multiple layers, the perfect design is to wind all the layers in the same winding direction and 
perfectly align all the air gaps in each layer in the same position, which can obtain a minimum and uniform distribution of magnetization loss among layers. However, this is not a reasonable solution considering the practicability and fabrication cost. A more reasonable design for multiple-layer CORC cables is that the cable has an even number of layers and adjacent two layers are wound in opposite winding direction. This can lead to a uniform distribution of magnetization losses among layers and relatively low magnetization losses.

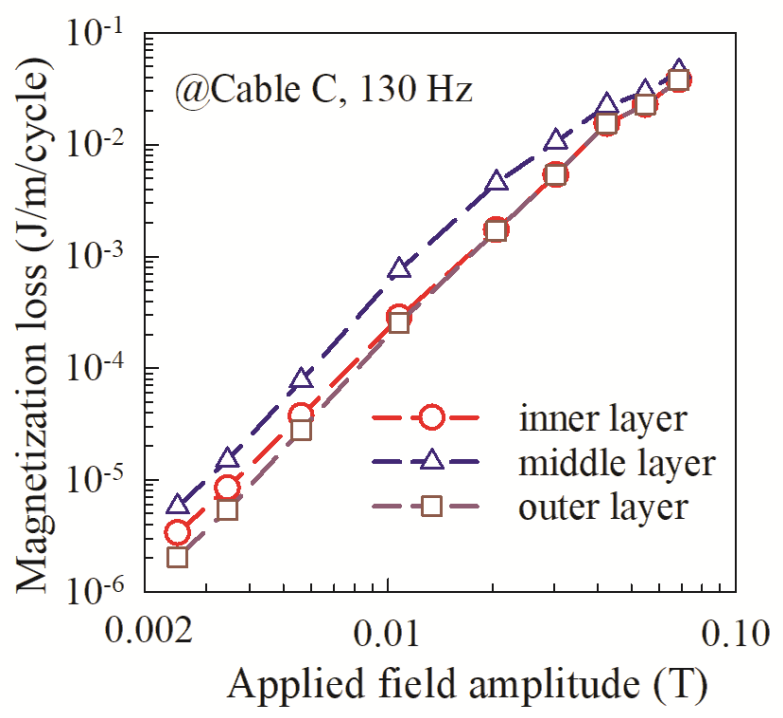

Figure 8. Magnetization loss calculated, in Joule per cycle per meter of cable length, $Q_{\text {cable }}$ of the three layers in Cable $\mathrm{C}$.

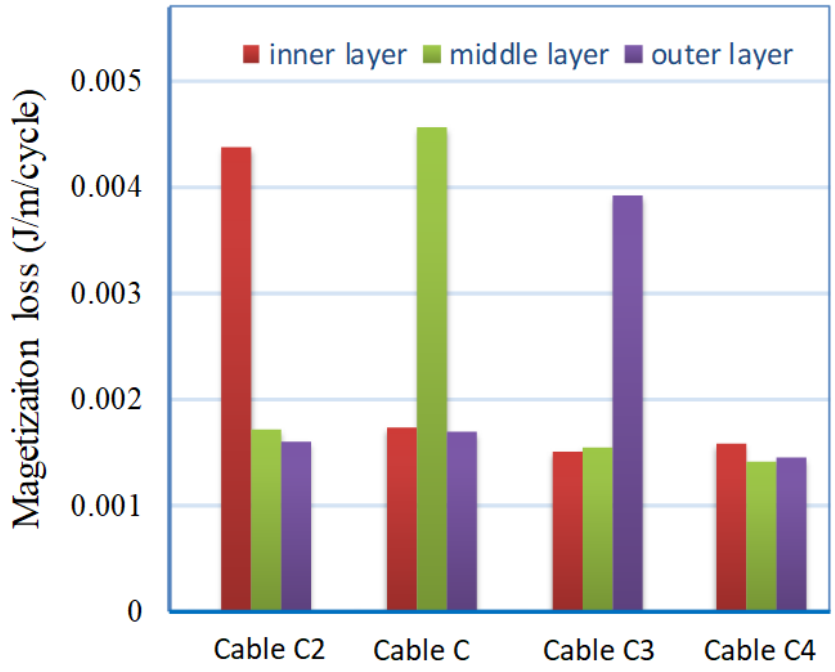

Figure 9. Magnetization loss distribution among three layers of Cable $C$, and its tree references, Cable C2, Cable C3 and Cable C4, applied field $20.5 \mathrm{mT} / 130 \mathrm{~Hz}$. 

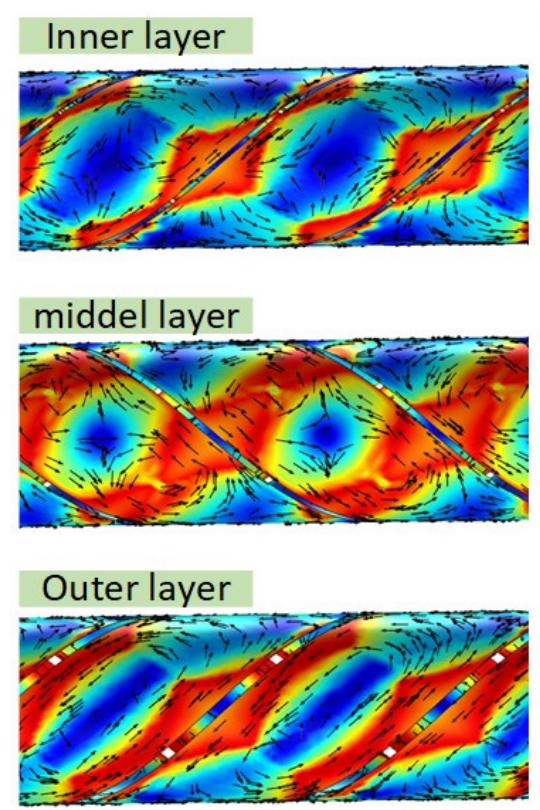

(a) Cable C

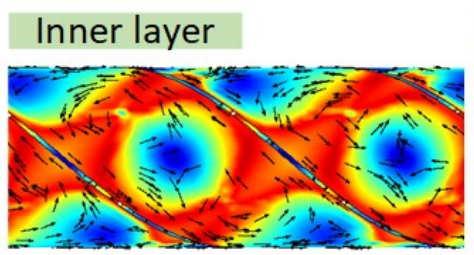

Inner layer

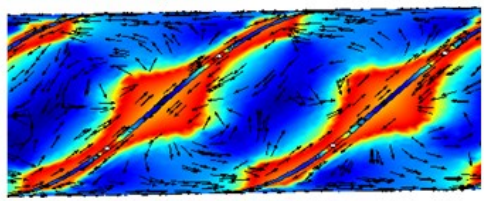

middel layer

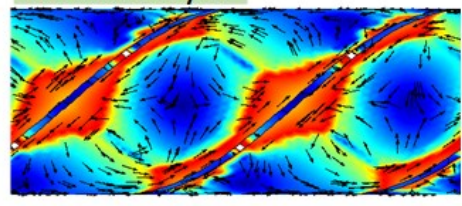

middel layer
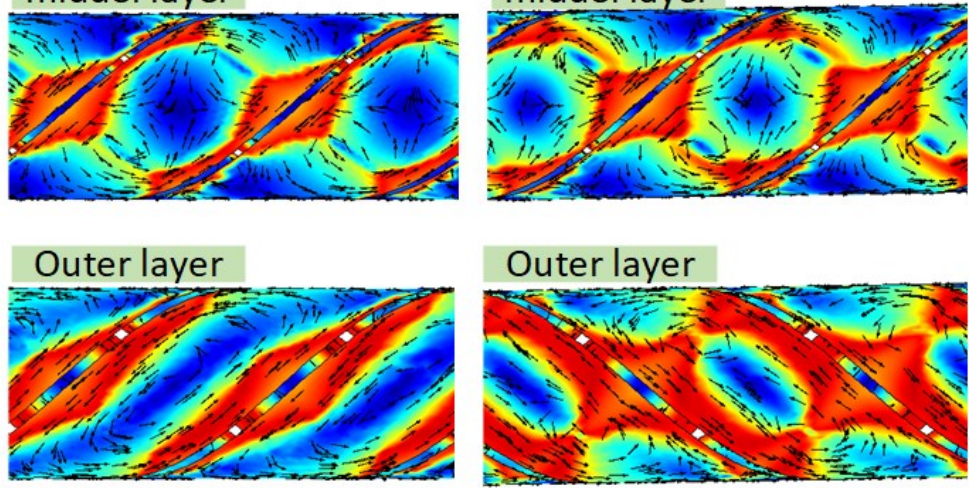

(b) Cable C2

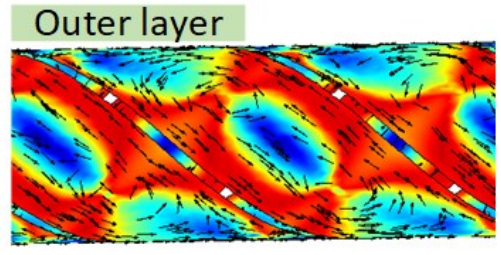

(c) Cable C3

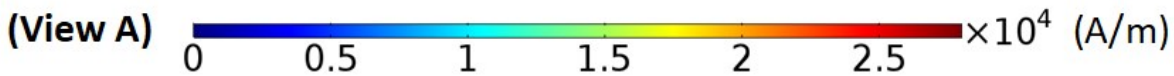

Figure 10. Distribution of the induced current density on three layers of Cable C, Cable C2, and Cable C3, at $t=3 \mathrm{~T} / 4$, the applied field, $20.5 \mathrm{mT} / 130 \mathrm{~Hz}$.

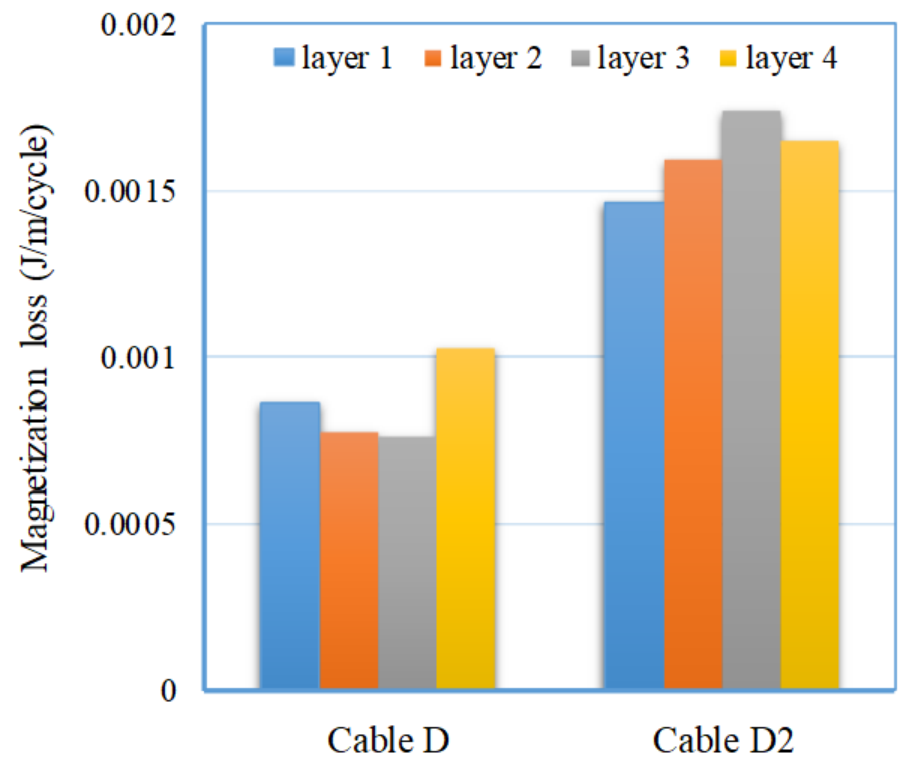

Figure 11. Magnetization loss distribution in CORC cables with four layers, applied field $20.5 \mathrm{mT} / 130 \mathrm{~Hz}$. In Cable D, the air gaps in four layers are aligned perfectly; In Cable D2, the $2^{\text {th }}$ and $4^{\text {th }}$ layer have an opposite winding direction with the other two layers. 


\subsection{Loss reduction using striated REBCO tapes}

A laser scribing technology has been applied on REBCO tapes to reduce AC losses, in which the superconducting layer of the tape is divided into filaments by laser scribing and meanwhile the substrate layer is kept for a mechanical support [38, 42]. This section focuses on the magnetization loss reduction using striated tapes for CORC cables. Simulations are performed on the striated counterparts of Cable A and Cable B, and the effect of filaments on magnetization loss is shown in Figure 12 and Figure 13. Here, to apply a simple variable method on the filament, the critical current of all the filaments is assumed uniform, the trench between filaments is neglected and the critical current reduction generated by the tape striation is neglected, though the critical current of REBCO tape shows a significant degradation when the number of filaments is more than five[36-38,59]. The coupling current between individual filaments is neglected by constraining the total current of each filament to be zero in the calculation. The results show that the tape striation technique shows very different effects on magnetization loss of CORC cables at low applied fields and high fields. At high magnetic fields, the tape striation can significantly reduce the magnetization loss, and the loss decreases continuously with the increase of filament number, as shown in Figure 13(b). At low magnetic fields (for example, B=5.6 mT), striated tapes leads to a higher magnetization loss when the number of filaments is small (less than 3 for Cable A at field $5.6 \mathrm{mT}$ ), after peak value, the magnetization loss drops continuously with the further increase of filaments, as shown in Figure 13(a). Nevertheless, this drop is much slower than that at high applied fields shown in Figure 13(b).

To understand this, we plot in Figure 14 the field shielding effect of CORC cables on the magnetic field inside CORC cable, here we define the field shielding factor $\eta$ as the ratio between the magnetic field at cable axis and the applied transverse fields. Figure 15 shows the distribution of normalized current density in Cable A under different filaments. The original tape without striation shows a relatively strong field shielding effect, and striated tape can significantly reduce the field shielding effects no matter low applied fields or high fields. At high applied fields, most areas of the REBCO tape is penetrated, striated tape can always significantly reduce the flux coupling as well as induced current, and therefore the magnetization loss drops continually with the increase of filaments. At low applied fields, most areas of the un-striated tape have no induced current, only the zones near edges are penetrated and the inner zones are shielded, as shown in Figure 15(a). Tape striation with a few filaments leads to more penetration on the inner zones of the tape and thus generates more magnetization loss [60]. Then, with the increase of filaments, the reduction of induced current shows a more significant influence on magnetization loss, therefore the loss starts to drop gradually with the increase of filaments. 
The results also show that striated tape has a much more magnetization loss reduction in CORC cable at high fields than that at low fields. At high fields, the loss reduction with filaments follows the function $1 / x$, in which $x$ represents the number of filaments. At low fields, although the loss also decreases with filaments after peak, it does not follow the above function. Thee crossover point is 5 10 mT for Cable A with single layer, and is about $20 \mathrm{mT}$ for Cable B with double layers, as shown in Figure 12. Cable B has a stronger field shielding effect than Cable A because of more layers, thus has a higher crossover field. Previous studies show that the tape's critical current degradation becomes more and more significant with the increase of filaments [36-38, 59]. Therefore, an optimization analysis is required on the number of filaments when the tape striation technique is applied on CORC cables in industrial applications.
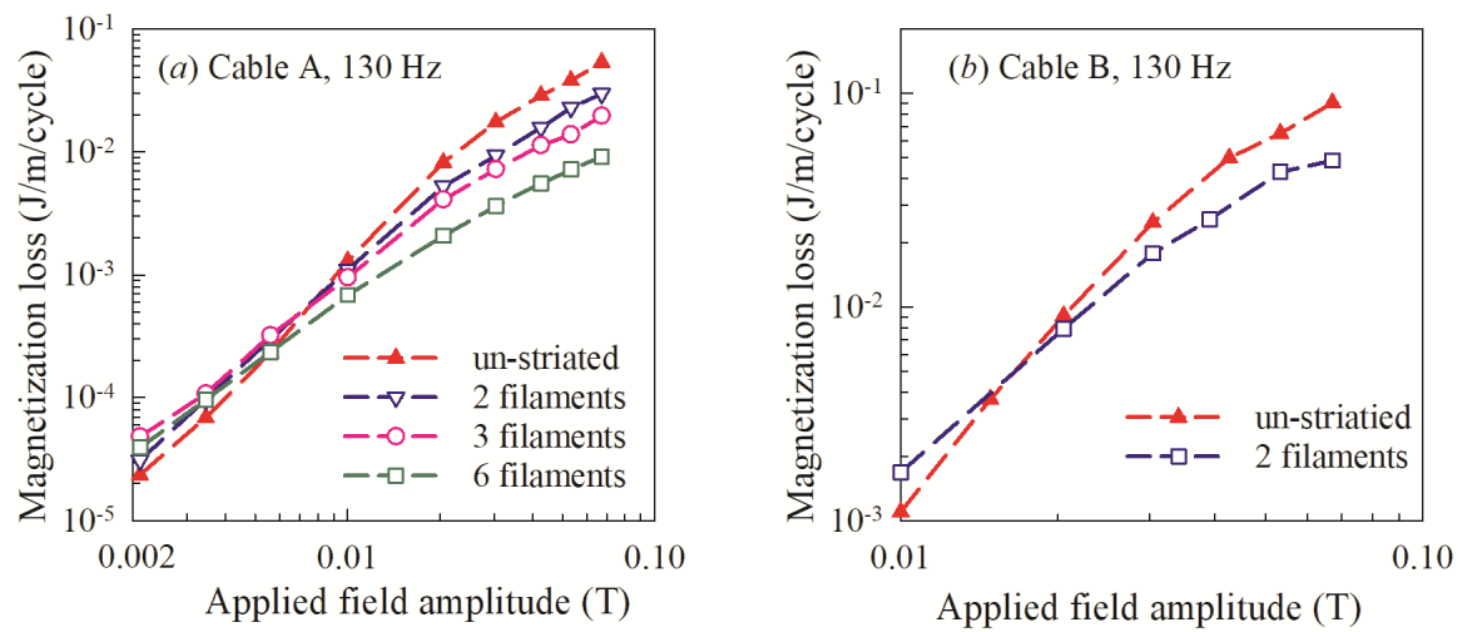

Figure 12. Effects of filaments on the magnetization loss, in Joule per cycle per meter of cable length, of CORC cables: Cable A with single layer and Cable B with double layers.
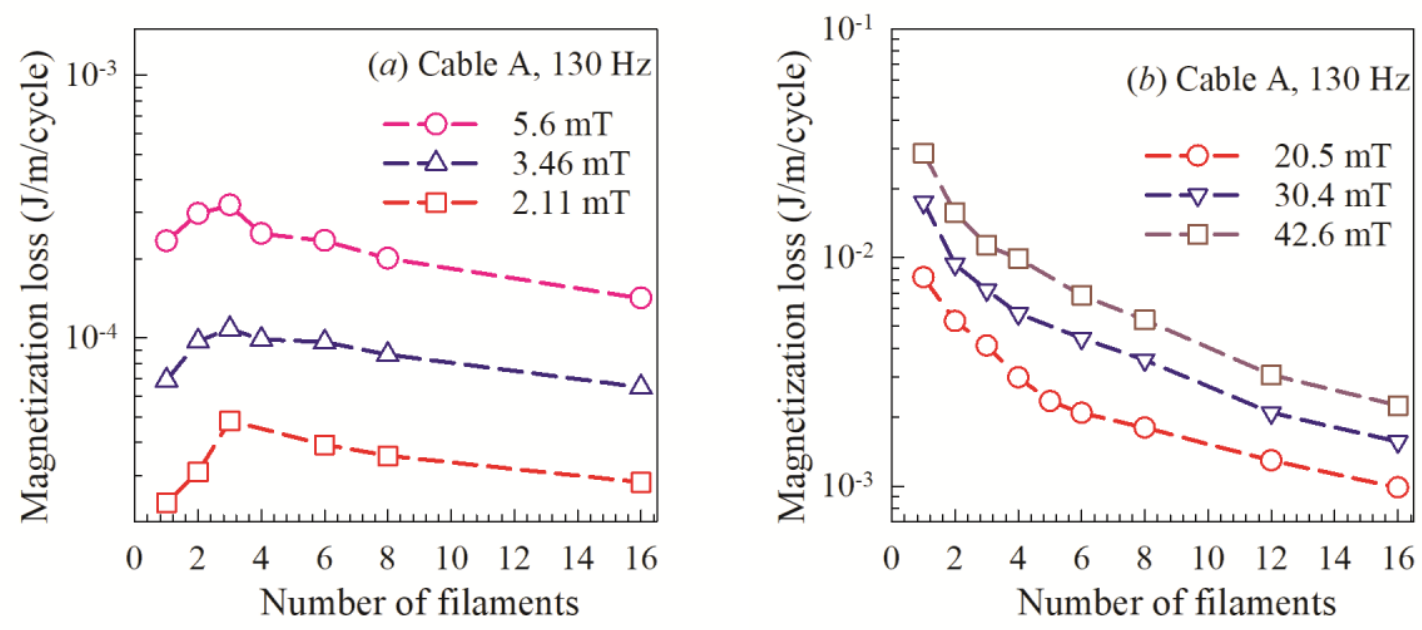
Figure 13. Dependence of magnetization loss on the number of filaments, Cable A.

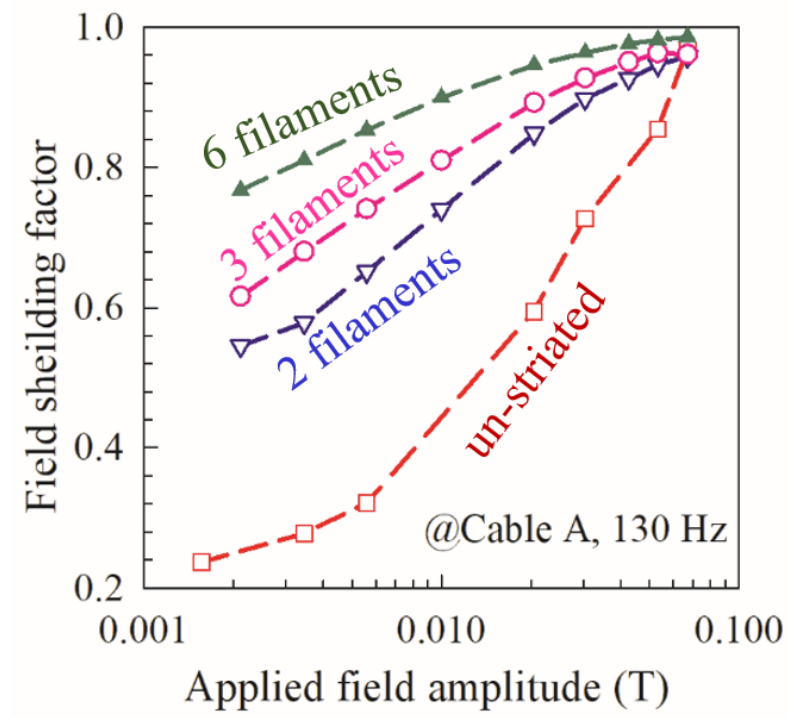

Figure 14. Effects of filaments on the field-shielding factor of Cable A with single layer.
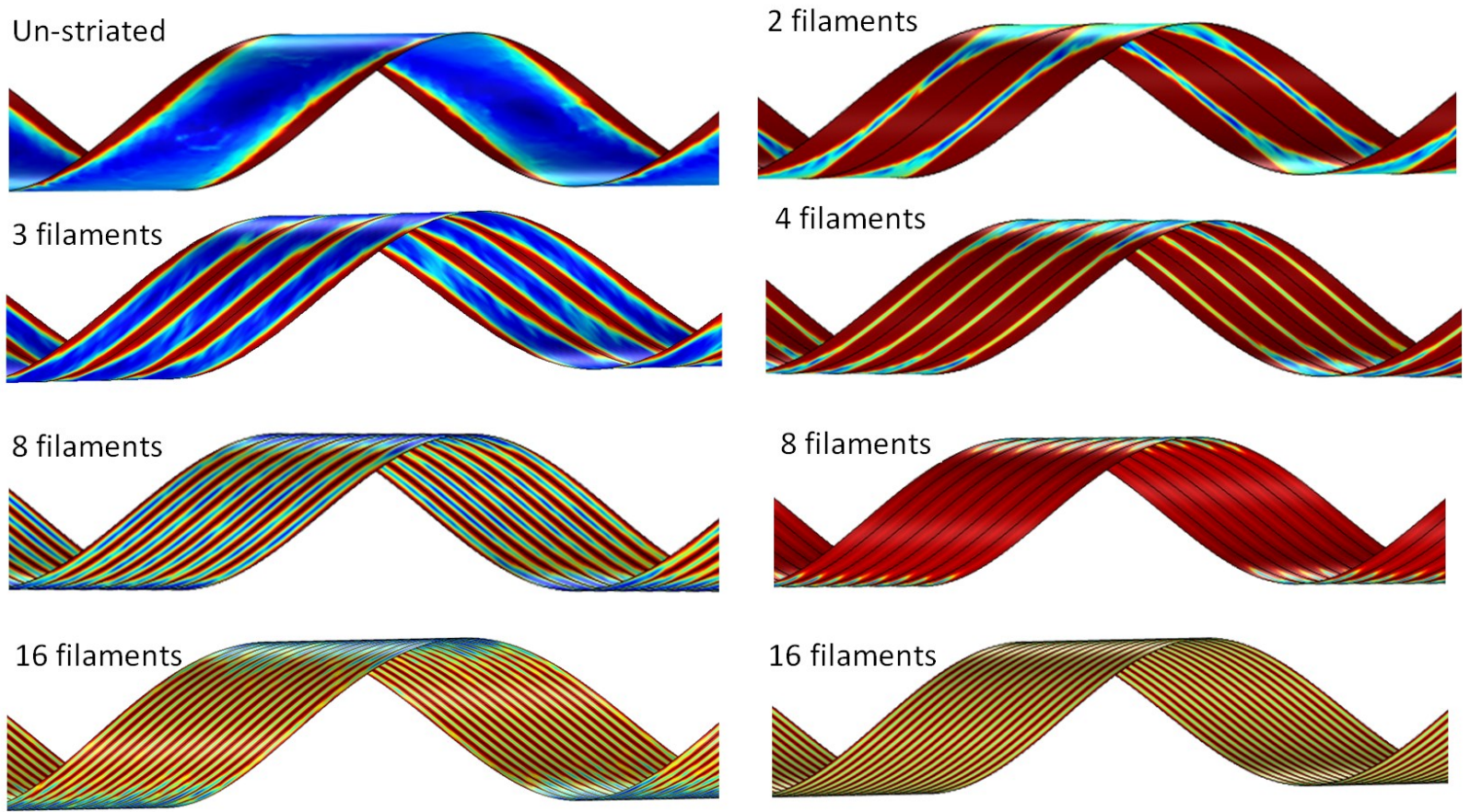

(a) $5.6 \mathrm{mT}$

(b) $20.5 \mathrm{mT}$

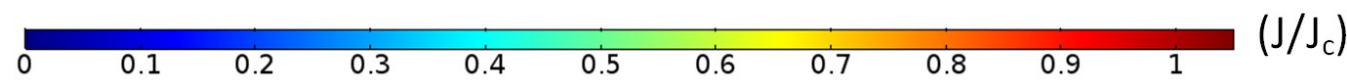

Figure 15. Filaments effects on the induced current distribution of Cable A: (a) at low applied field $5.6 \mathrm{mT}$, (b) high applied field $20.5 \mathrm{mT} .130 \mathrm{~Hz}, t=3 \mathrm{~T} / 4$, (View A). 


\section{Conclusions}

This paper studied the magnetization losses of CORC cables using a 3D model based on the T-A formulation. The model was validated by experimental measurements published by other groups. The current distribution and magnetization losses induced by an external magnetic field were studied for CORC cables with different layers. The influence of striated tapes on the magnetization loss is analyzed and discussed. In CORC cables, induced current is divided into small local current loops by the helical winding structure, and each pitch has two current loops with opposite current directions. In comparison to a single tape, the magnetization loss reduction on CORC cables is caused by not only the reduction of induced current, but also the current offset of two adjacent current loops. The CORC cable losses per tape decrease with the increase of cable layers, due to the field shielding effects.

For CORC cables with multiple layers, the magnetization loss is significantly affected by winding direction and packing arrangement of air gaps in each layer. An inadequate structure may lead to not only higher magnetization loss but also considerable non-uniform distribution of magnetization loss among layers. When all the layers are wound in the same direction and the air gaps in each layer is perfectly aligned, the cable generates minimum magnetization loss and the loss shows a uniform distribution among layers. However, considering practicability and easy fabrication, a reasonable design for multiple-layer CORC cables is that where the cable has an even number of layers and adjacent two layers are wound in opposite winding. This can lead to a uniform distribution of magnetization losses among layers and the loss is also relatively low.

The tape striation technique shows very different effects on magnetization loss of CORC cables at low applied fields and high fields. At low magnetic fields, striated tapes leads to a higher magnetization loss when the number of filaments is small, after peak value, the magnetization loss drops continuously with the further increase of filaments. At high magnetic fields, the tape striation can significantly reduce the magnetization loss, and the loss decreases continuously with the increase of filament number. This loss reduction is much more significant than that at low applied fields. Considering the degradation of the tape's critical current, optimization is required on the number of filaments in design of CORC cables.

\section{Acknowledgments}

This project was supported by EPSRC grant EP/P002277/1. The authors would like to thank Dr. Anna Kario (Karlsruhe Institute of Technology) for sharing useful information about the geometry and structure of CORC cables. Dr Min Zhang would like to thank the support of Royal Academy of Engineering 
Research Fellowship. Dr Yawei Wang would like to thank the support of European Union's Horizon 2020 research and innovation programme under the Marie Sklodowska-Curie grant agreement No 799902.

\section{References}

[1] Obradors X and Puig T 2014 Coated conductors for power applications: materials challenges Supercond. Sci. Technol.27 044003

[2] Samoilenkov S, Molodyk A, Lee S, Petrykin V, Kalitka V, Martynova I, Makarevich A, Markelov A, Moyzykh M and Blednov A 2016 Customised 2G HTS wire for applications Supercond. Sci. Technol.29 024001

[3] Wang X, Caspi S, Dietderich D et al 2018 A viable dipole magnet concept with REBCO CORC ${ }^{\circledR}$ wires and further development needs for high-field magnet applications Supercond. Sci. Technol.31 045007

[4] Berg F, Palmer J, Miller P and Dodds G 2017 HTS System and Component Targets for a Distributed Aircraft Propulsion System IEEE Trans. Appl. Supercond. 273600307

[5] van der Laan D C, Weiss J D, Noyes P, Trociewitz U P, Godeke A, Abraimov D and Larbalestier D C 2016 Record current density of 344Amm(-2) at 4.2K and 17T in CORC (R) accelerator magnet cables Supercond. Sci. Technol.29 055009

[6] Mulder T, Dudarev A, Mentink M, Silva H, van der Laan D, Dhalle M and ten Kate H 2016 Design and Manufacturing of a $45 \mathrm{kA}$ at 10 T REBCO-CORC Cable-in-Conduit Conductor for Large-Scale Magnets IEEE Trans. Appl. Supercond. 264803605

[7] Michael P C, Bromberg L, van der Laan D C, Noyes P and Weijers H W 2016 Behavior of a high-temperature superconducting conductor on a round core cable at current ramp rates as high as $67.8 \mathrm{kAs}(-1)$ in background fields of up to 19T Supercond. Sci. Technol.29 045003

[8] van der Laan D C, Goodrich L F, Noyes P, Trociewitz U P, Godeke A, Abraimov D, Francis A and Larbalestier D C 2015 Engineering current density in excess of $200 \mathrm{Amm}(-2)$ at $20 \mathrm{~T}$ in CORC (R) magnet cables containing RE-Ba2Cu3O7delta tapes with $38 \mathrm{mu}$ m thick substrates Supercond. Sci. Technol.28 124001

[9] Li J W, Wang X D, Zhang Z Y, Le Blond S, Yang Q Q, Zhang M and Yuan W J 2017 Analysis of a new design of the hybrid energy storage system used in the residential m-CHP systems Applied Energy 187 169-79

[10] Wang Y W, Zhang M, Yuan W J, Hong Z Y, Jin Z J and Song H H 2017 Non-uniform ramping losses and thermal optimization with turn-to-turn resistivity grading in a (RE) Ba2Cu3Ox magnet consisting of multiple no-insulation pancake coils J. Appl. Phys. 122053902

[11] Song X, Mijatovic N, Kellers J, Bührer C, Rebsdorf A V, Hansen J, Christensen M, Krause J, Wiezoreck J, Pütz H and Holbøll J 2017 A Full-Size High-Temperature Superconducting Coil Employed in a Wind Turbine Generator Setup IEEE Trans. Appl. Supercond. 27 1-5

[12] Zhang M, Yuan W, Kvitkovic J and Pamidi S 2015 Total AC loss study of 2G HTS coils for fully HTS machine applications Supercond. Sci. Technol.28 115011

[13] Yuan W, Venuturumilli S, Zhang Z, Mavrocostanti Y and Zhang M 2018 Economic Feasibility Study of Using HighTemperature Superconducting Cables in U.K.\&\#x0027;s Electrical Distribution Networks IEEE Trans. Appl. Supercond. $281-5$

[14] Wang Y, Wang P, Li K, Song H, Yang J, Ma C, Jin Z and Hong Z 2017 Analysis and Comparison Between No-insulation and Metallic Insulation REBCO Magnet for the Engineering Design of a 1 MW DC Induction Heater IEEE Trans. Appl. Supercond. 273700105

[15] Li J W, Yang Q Q, Robinson F, Liang F, Zhang M and Yuan W J 2017 Design and test of a new droop control algorithm for a SMES/battery hybrid energy storage system Energy 118 1110-22

[16] Goldacker W, Frank A, Heller R, Schlachter S I, Ringsdorf B, Weiss K P, Schmidt C and Schuller S 2007 ROEBEL assembled coated conductors (RACC): Preparation, properties and progress IEEE Trans. Appl. Supercond. 17 3398-401

[17] Zermeno V M R, Grilli F and Sirois F 2013 A full 3D time-dependent electromagnetic model for Roebel cables Supercond. Sci. Technol.26 052001

[18] Goldacker W, Grilli F, Pardo E, Kario A, Schlachter S I and Vojenciak M 2014 Roebel cables from REBCO coated conductors: a one-century-old concept for the superconductivity of the future Supercond. Sci. Technol.27 093001

[19] Long N J, Badcock R A, Hamilton K, Wright A, Jiang Z and Lakshmi L S 2010 Development of YBCO Roebel cables for high current transport and low AC loss applications Journal of Physics: Conference Series 234022021

[20] Badcock R A, Long N J, Mulholland M, Hellmann S, Wright A and Hamilton K A 2009 Progress in the Manufacture of Long Length YBCO Roebel Cables IEEE Trans. Appl. Supercond. 19 3244-7

[21] Takayasu M, Chiesa L, Bromberg L and Minervini J V 2012 HTS twisted stacked-tape cable conductor Supercond. Sci. Technol.25 014011

[22] Takayasu M, Chiesa L, Noyes P D and Minervini J V 2017 Investigation of HTS Twisted Stacked-Tape Cable (TSTC) Conductor for High-Field, High-Current Fusion Magnets IEEE Trans. Appl. Supercond. 276900105 
[23] Laan D C v d 2009 YBa 2 Cu 3 O 7- $\delta$ coated conductor cabling for low ac-loss and high-field magnet applications Supercond. Sci. Technol.22 065013

[24] Laan D C v d, Lu X F and Goodrich L F 2011 Compact GdBa 2 Cu 3 O 7- $\delta$ coated conductor cables for electric power transmission and magnet applications Supercond. Sci. Technol.24 042001

[25] Weiss J D, Mulder T, ten Kate H J and van der Laan D C 2017 Introduction of CORC (R) wires: highly flexible, round high-temperature superconducting wires for magnet and power transmission applications Supercond. Sci. Technol.30 014002

[26] Majoros M, Sumption M D, Collings E W and van der Laan D C 2014 Magnetization losses in superconducting YBCO conductor-on-round-core (CORC) cables Supercond. Sci. Technol.27 125008

[27] Terzioglu R, Vojenciak M, Sheng J, Gomory F, Ccedil;avus T F and Belenli I 2017 AC loss characteristics of CORC((R))cable with a Cu former Supercond. Sci. Technol.30 085012

[28] Solovyov M, Souc J and Gomory F 2014 AC loss properties of single-layer CORC cables, J. Phys.: Conf. Series, vol. 507, no. 2.

[29] Gömöry F, Šouc J, Vojenčiak M, Terzioglu R and Frolek L 2017 Design and Testing of Coils Wound Using the ConductorOn-Round-Tube (CORT) Cable IEEE Trans. Appl. Supercond. 27 1-5

[30] Grilli F and Kario A 2016 How filaments can reduce AC losses in HTS coated conductors: a review Supercond. Sci. Technol.29 083002

[31] Xing D, Patel J, Sun Q, Zhu J, Zhang G, Liang F, Yuan W and Zhang M 2017 AC Loss Comparison Between Multifilament and Nonstriated YBCO Coils Designed for HTS Propulsion Motors IEEE Trans. Appl. Supercond. 27 1-5

[32] Sumption M D, Collings E W and Barnes P N 2005 AC loss in striped (filamentary) YBCO coated conductors leading to designs for high frequencies and field-sweep amplitudes Supercond. Sci. Technol.18 122

[33] Amemiya N, Kasai S, Yoda K, Jiang Z, Levin G, Barnes P N and Oberly C E 2004 AC loss reduction of YBCO coated conductors by multifilamentary structure Supercond. Sci. Technol.17 1464

[34] Levin G A, Murphy J, Haugan T J, Šouc J, Kováč J and Kováč P 2013 AC Losses of Copper Stabilized Multifilament YBCO Coated Conductors IEEE Trans. Appl. Supercond. 236600604

[35] Jiang Z, Amemiya N, Ayai N and Hayashi K 2004 Total AC loss characteristics of untwisted and twisted Bi-2223 multifilamentary tapes and interaction between self and external magnetic fields Supercond. Sci. Technol.17 1311

[36] Demenčík E, Vojenčiak M, Kario A, Nast R, Jung A, Goldacker W and Grilli F 2014 AC Loss and Coupling Currents in YBCO Coated Conductors With Varying Number of Filaments IEEE Trans. Appl. Supercond. 246601008

[37] Šouc J, Gömöry F, Kováč J, Nast R, Jung A, Vojenčiak M, Grilli F and Goldacker W 2013 Low AC loss cable produced from transposed striated CC tapes Supercond. Sci. Technol.26 075020

[38] Vojenciak M, Kario A, Ringsdorf B, Nast R, van der Laan D C, Scheiter J, Jung A, Runtsch B, Gomory F and Goldacker W 2015 Magnetization ac loss reduction in HTS CORC (R) cables made of striated coated conductors Supercond. Sci. Technol.28 104006

[39] Li Q, Tan H and Yu X 2014 Effect of Multilayer Configuration on AC Losses of Superconducting Power Transmission Cables Consisting of Narrow Coated Conductors IEEE Trans. Appl. Supercond. 245400604

[40] Sheng J, Vojenčiak M, Terzioğlu R, Frolek L and Gömöry F 2017 Numerical Study on Magnetization Characteristics of Superconducting Conductor on Round Core Cables IEEE Trans. Appl. Supercond. 274800305

[41] Fukui S, Noguchi T, Ogawa J, Yamaguchi M, Sato T, Tsukamoto O and Takao T 2007 Numerical Study on AC Loss Minimization of Multi-Layer Tri-Axial HTS Cable for 3-Phase AC Power Transmission IEEE Trans. Appl. Supercond. 17 1700-3

[42] Jiang Z, Amemiya N and Nakahata M 2008 Numerical calculation of AC losses in multi-layer superconducting cables composed of coated conductors Supercond. Sci. Technol.21 025013

[43] Song X, Mijatovic N, Zou S, Jensen B B and Holbøll J 2016 AC Losses and Their Thermal Effect in High-Temperature Superconducting Machines IEEE Trans. Appl. Supercond. 265900105

[44] Zhu Z, Wang Y, Venuturumilli S, Sheng J, Zhang M and Yuan W 2018 Influence of Harmonic Current on Magnetization Loss of a Triaxial CORC REBCO Cable for Hybrid Electric Aircraft IEEE Trans. Appl. Supercond. 285900405

[45] Stenvall A, Siahrang M, Grilli F and Sirois F 2013 Computation of self-field hysteresis losses in conductors with helicoidal structure using a 2D finite element method Supercond. Sci. Technol.26 045011

[46] Takeuchi K, Amemiya N, Nakamura T, Maruyama O and Ohkuma T 2011 Model for electromagnetic field analysis of superconducting power transmission cable comprising spiraled coated conductors Supercond. Sci. Technol.24 085014

[47] Amemiya N, Nishino R, Takeuchi K, Nii M, Nakamura T, Yagi M and Okuma T 2013 Ac loss analyses of superconducting power transmission cables considering their three-dimensional geometries Physica C-Superconductivity and Its Applications 484 148-52

[48] Zhang H, Zhang M and Yuan W 2016 An efficient 3D finite element method model based on the T-A formulation for superconducting coated conductors Supercond. Sci. Technol.30 024005

[49] Liang F, Venuturumilli S, Zhang H, Zhang M, Kvitkovic J, Pamidi S, Wang Y and Yuan W 2017 A finite element model for simulating second generation high temperature superconducting coils/stacks with large number of turns J. Appl. Phys. 122043903

[50] Takeuchi K, Amemiya N, Nakamura T, Maruyama O and Ohkuma T 2011 Model for electromagnetic field analysis of superconducting power transmission cable comprising spiraled coated conductors Supercond. Sci. Technol.24 085014 
[51] Grilli F, Sirois F, Zermeno V M R and Vojenciak M 2014 Self-Consistent Modeling of the Ic of HTS Devices: How Accurate do Models Really Need to Be? IEEE Trans. Appl. Supercond. 24

[52] Kajikawa K, Hayashi T, Yoshida R, Iwakuma M and Funaki K 2003 Numerical evaluation of AC losses in HTS wires with 2D FEM formulated by self magnetic field IEEE Trans. Appl. Supercond. 13 3630-3

[53] Zermeno V M R, Abrahamsen A B, Mijatovic N, Jensen B B and Sorensen M P 2013 Calculation of alternating current losses in stacks and coils made of second generation high temperature superconducting tapes for large scale applications J. Appl. Phys. 114173901

[54] Wang Y, Song H, Yuan W, Jin Z and Hong Z 2017 Ramping turn-to-turn loss and magnetization loss of a No-Insulation (RE) Ba2Cu3Ox high temperature superconductor pancake coil J. Appl. Phys. 121113903

[55] Queval L, Zermeno V M R and Grilli F 2016 Numerical models for ac loss calculation in large-scale applications of HTS coated conductors Supercond. Sci. Technol.29 024007

[56] Jiang Z, Zhou W, Li Q, Yao M, Fang J, Amemiya N and Bumby C B 2018 The dynamic resistance of YBCO coated conductor wire: effect of DC current magnitude and applied field orientation Supercond. Sci. Technol.31 035002

[57] Iwakuma M, Toyota K, Nigo M, Kiss T, Funaki K, Iijima Y, Saitoh T, Yamada Y and Shiohara Y 2004 AC loss properties of YBCO superconducting tapes fabricated by IBAD-PLD technique Physica C: Superconductivity 412-414 983-91

[58] Jiang Z, Amemiya N, Kakimoto K, Iijima Y, Saitoh T and Shiohara Y 2008 The dependence of AC loss characteristics on the space in stacked YBCO conductors Supercond. Sci. Technol.21 015020

[59] Ben Yahia A, Li X F, Majoros M, Sumption M D and Selvamanickam V 2017 AC Loss Reduction in Multifilamentary Coated Conductors With Transposed Filaments IEEE Trans. Appl. Supercond. 275600105

[60] Marchevsky M, Zhang E, Xie Y, Selvamanickam V and Ganesan P G 2009 AC Losses and Magnetic Coupling in Multifilamentary 2G HTS Conductors and Tape Arrays IEEE Trans. Appl. Supercond. 19 3094-3097 